\title{
MORE THAN MEETS THE EYE: RELATIONAL AUTONOMY AND DECISION- MAKING BY ADULTS WITH DEVELOPMENTAL DISABILITIES
}

\author{
Eniola Salami* \\ Bonnie Lashewicz**
}

In Canadian law, the concept of autonomy is individualistic in nature, manifest as the capacity, or legal ability of an individual to actively understand the purpose and consequences of their actions according to whether they have faculties to comprehend and weigh risks and benefits. Feminist scholars critique such conceptualizations of autonomy and, instead, argue the importance of "relational autonomy" which is predicated on the view that actions result from one's own volition in combination with the influence of one's social and relational connections. In this paper, we examine the dynamics and implications of relational autonomy in decision-making by adults with developmental disabilities by studying adults with developmental disabilities in interaction with their caregiving family members. Our purpose is to contribute understandings of how and in what ways family caregiving relational contexts both support and hinder decision-making by adults with developmental disabilities. We begin with an overview of conceptualizations and applications of autonomy, then illustrate relational autonomy dynamics through comparative analysis of data from two women with developmental disabilities who were interviewed together with their family caregivers about successes and struggles in giving and receiving care and making decisions. These two women, and their family caregivers $(N=9)$ are selected from a larger sample of adults with developmental disabilities and their family caregivers $(N=26)$ because the contrasts, as well as the similarities, between their family care situations are striking, and taken together, illustrate a range of ways in which decision-making is supported and hindered. We conclude by upholding the importance of relational autonomy for legal understandings of decision-making, yet we caution that critical examination of relationship dynamics is vital.

En droit canadien, le concept de l'autonomie est un concept individualiste de par sa nature et est perçu comme l'aptitude, physique ou juridique, d'une personne à comprendre activement l'objet et les conséquences de ses actes en fonction de la question de savoir si elle possède les facultés voulues pour apprécier et soupeser les risques et les avantages en jeu. Des universitaires féministes critiquent ces conceptualisations de l'autonomie et mettent plutôt l'accent sur l'importance de l' " autonomie relationnelle ", qui repose sur l'interaction entre la volonté de la personne et l'influence de ses contacts sociaux et relationnels. Dans le présent

* BHSc., University of Calgary

** PhD., University of Calgary 
document, nous nous penchons sur la dynamique et sur les incidences de l'autonomie relationnelle dans les décisions que prennent les adultes handicapés en étudiant l'interaction d'adultes handicapés avec leurs aidants familiaux. Notre but est de favoriser une meilleure compréhension de la mesure dans laquelle les contextes relationnels dans lesquels se trouvent les aidants familiaux peuvent à la fois appuyer et entraver le processus de prise de décisions chez les adultes handicapés. Après avoir présenté un bref aperçu des conceptualisations et des applications de l'autonomie, nous illustrons la dynamique de l'autonomie relationnelle au moyen d'une analyse comparative de données provenant de deux femmes handicapées qui ont été interrogées ainsi que leurs aidants familiaux au sujet des défis et des réussites liés à la prestation et à la réception de soins et à la prise de décisions. Ces deux femmes et leurs aidants familiaux $(N=9)$ ont été choisis à partir d'un plus grand échantillon d'adultes handicapés et de leurs aidants familiaux $(N=26)$, parce que les contrastes, tout comme les similitudes, entre leurs situations sont frappants et que, examinées ensemble, ces données illustrent différentes façons dont la prise de décisions est appuyée et entravée. Nous concluons en insistant sur l'importance de l'autonomie relationnelle pour la compréhension des aspects juridiques de la prise de décisions, tout en soulignant qu'un examen critique de la dynamique des relations est vital.

\section{INTRODUCTION}

In Canadian law, the concept of autonomy is manifest in capacity, defined as the legal ability of an individual to actively comprehend the purposes and consequences of their actions according to whether they have the faculties to weigh benefits and risks. ${ }^{1}$ Considerable legal resources are invested to sophisticatedly apply the concept of capacity by distinguishing between an individual's failure to appreciate risks, versus an individual's inability to appreciate risks. ${ }^{2}$ Accordingly, the law makes it clear that consensus about the wisdom of an individual's decisions is not required as evidence of that individual's capacity. Yet, capacity continues to be to be treated in terms of traditional conceptions of autonomy focused on the ability for individuals to make unified, rational, and self-aware decisions as the requisite for autonomous action ${ }^{3}$. In this understanding of autonomy, emphasis is on independence, or the ability to carry out courses of action in an atomistic or isolated fashion. ${ }^{4}$

Feminist scholars have criticized the traditional conception of autonomy for being highly masculinized, individualistic, rationalistic, and serving to set up the independent, rational and

Jim Conway, Core 573: Disability and the Law (Community Rehabilitation and Disability Studies, University of Calgary, 2012).

2 See e.g. Koch (Re) 1997, 33 OR (3d) 485, 1997 Can-LII1 2138; Starson v. Swayze, 2003 SCC 32, [2002] 1 SCR 722 .

3 Catriona Mackenzie \& Natalie Stoljar, "Introduction: Autonomy Reconfigured" in Catriona Mackenzie \& Natalie Stoljar, eds, Relational Autonomy: Feminist Perspectives on Autonomy, Agency, and the Social Self (New York: Oxford University Press, 2000) 3.

$4 \quad$ Ibid 
self-determining male as the archetype for sound decision-making. ${ }^{5}$ These scholars argue that the traditional preoccupation with autonomy as "self-sufficient independence" obscures the embeddedness of individuals in their social contexts, essentially ignoring how one's social position and close relationships affect decision-making. ${ }^{6}$ In 1978, Chodorow set the stage for interrogation of self-sufficiency-focused definitions of autonomy as she called attention to the false dichotomy of viewing autonomy as the opposite of dependence on, or close connection to, others. ${ }^{7}$ These currents of criticism are being taken up by legal scholars. Hall, for example, challenges the legal convention of intertwining autonomy with mental capacity and argues the problematic nature of treating mental incapacity as a medically ascertainable state. ${ }^{8}$ Working to disentangle concepts, Hall discusses autonomy in relational terms as developing across time and in relationship with others.

Bach and Kerzner echo Hall's line of thinking as they argue for greater efforts to protect and advance the legal capacity of individuals. ${ }^{9}$ Aligning with feminist scholarship, Bach and Kerzner present autonomy as a social and interdependent accomplishment; they propose a minimal threshold for recognizing an individual's capability in directing his/her own life as an individual's ability to act in a way that can be understood as meaningful by at least one person. Thus, legal capacity is defined not only by an individual's abilities, but also by their relationships of support.

In this paper, we add our critique of atomistic legal conceptions of capacity as incompatible with the experiences and needs of marginalized groups for whom individualistic decisionmaking is not possible. We use the feminist conception of relational autonomy in our effort to contribute to more inclusive understandings of autonomy. We begin with an overview of conceptualizations and applications of relational autonomy concepts followed by a definition of the population to whom we apply these concepts, namely adults with developmental disabilities and their family caregivers. We then illustrate relational autonomy dynamics through comparative analysis of data from two women with developmental disabilities who were interviewed, together with their family caregivers, about successes and struggles in giving and receiving support and making decisions. We conclude by upholding the importance of relational autonomy for legal understandings of decision-making, yet we caution that critical examination of relationship dynamics is vital.

\footnotetext{
Ibid

6 Susan Sherwin, No longer patient: Feminist ethics and health care. Philadelphia: Temple University Press, 1992.) Lorraine Code, "What can she know?: Feminist Theory and Construction of Knowledge" (Ithaca, NY: Cornell University Press, 1991); Mackenzie \& Stoljar, supra note 3.

7 Nancy Chodorow, The Reproduction of Mothering: Psychoanalysis and the Sociology of Gender (Berkeley: University of California Press, 1978).

8 Margaret Isabel Hall, "Mental Capacity in the (Civil) Law: Capacity, Autonomy and Vulnerability" (2012) 58:1 McGill LJ, 61.

9 Michael Bach \& Lana Kerzner, "A New Paradigm for Protecting Autonomy and the Right to Legal Capacity" (Toronto: Law Commission of Ontario, 2010), online: Law Commission of Ontario <http://www.lcocdo.org/en/disabilities-call-for-papers-bach-kerzner>.
} 


\section{A. Relational Autonomy and Answerability}

Relational autonomy is not a single concept with a singular definition, but rather a specific way of conceptualizing what it means to be a "free and self-governing agent". ${ }^{10}$ At its core, relational autonomy entails an emphasis on how individuals are "socially constituted" agents who define their principles and express their will or intent by making decisions based on their social connections, commitments and interdependencies. ${ }^{11}$ According to this framing of autonomy, individual decision-making occurs in the context of interpersonal processes which are part of social connections and interdependencies; individuals practice what Westlund terms "answerability" as they are simultaneously supported and constrained in decisions which depend, at least in part, on being answerable to considerations raised by others. ${ }^{12}$

Westlund illustrates answerability using two examples of "traditional wives", one which she calls deferent, the other she terms anti-feminist. ${ }^{13}$ The deferent wife consistently aligns her own will with the will of another (her husband). Rather than pursuing individual interests, she unquestioningly endorses her husband's interests about where to live and with whom to socialize, for example. This uncritical reliance on, and organizing around, the will of another constitutes what Westlund characterizes as "abdication of a certain form of responsibility for herself". ${ }^{14}$ Comparatively, the anti-feminist wife may live a life that, on the surface, closely resembles that of the deferent wife, yet the anti-feminist wife is distinguished by her readiness to discuss and justify her lifestyle to those who challenge her choices. While the deferent wife seems swept along with her husband's decisions, the anti-feminist wife holds herself answerable for her lifestyle and will argue, for example, that women ought to defer to their husbands' interests in the service of family values or religious principle.

Through such illustration, Westlund builds her case for the importance of "dialogical" interactions in which agents assess the preferences of other agents and respond to the "normative pressures" raised during this dialogical process. ${ }^{15}$ Thus, an autonomous agent is one who has the potential, or demonstrable ability, to vouch for, or assert, a preference in light of the preferences and criticisms of others. In this way, autonomy depends on the process of exchange between actors rather than actors' capacity for critical reflection. Although Westlund's discussion of 'dialogue' between agents conjures images of verbal exchange, Westlund does not specify answerability as a verbal process. ${ }^{16}$ Rather, Westlund's conception of exchange between agents includes communication through body language and facial expression. For instance, Westlund discusses an individual with a cognitive disability who is answerable through her non-verbal refusal of a medical action; this individual asserts her preference to not be treated by refusing to

10 John Christman, "Relational Autonomy, Liberal Individualism, and the Social Constitution of Selves" (2004) 117 Philosophical Studies 143 at 143.

11 Ibid; Holger Baumann, "Reconsidering relational autonomy. Personal autonomy for socially embedded and temporally extended selves" (2008) 30:2 Analyse \& Kritik 445.

12 Andrea C Westlund, "Rethinking Relational Autonomy (2009) 24:4 Hypatia 26.

13 Selflessness and responsibility for self: The implications of deference for autonomy, shared agency \& love. Unpublished PhD dissertation, University of Michigan.

$14 \quad$ Ibid at 2.

15 Westlund, supra note 12 at 1.

16 Ibid at 26-49. 
enter the dialogical process with her medical team. ${ }^{17}$ 'Answerability' then, is not an inherently verbal concept, but rather a process of exchange that may take any number of forms. Thus, whatever the mode of exchange, it is the interaction between 'answerable agents' and the quality of being 'answerable' for one's preferences that makes up the 'relational' aspect of relational autonomy.

\section{B. Building Autonomy Competency}

While Westlund uses her concept of answerability to explicate how and in what ways autonomy can be relational, ${ }^{18}$ Meyers' concept of 'autonomy competency' operationalizes the relational character of autonomy. ${ }^{19}$ Meyers presents autonomy competency to support her argument that marginalized individuals can gain partial autonomy based on their potential to develop "introspective, imaginative, reasoning and volitional skills" through social connections with others. ${ }^{20}$ Like Westlund, Meyers' illumination of autonomy was centred on women's roles within traditionally structured families. Meyers studied "traditional housewives" (who stay home and do not pursue paid employment) and argued that rather than being innate, autonomy is acquired and incremental. To illustrate, Meyers distinguished that "dependent" individuals can exercise episodic autonomy through the immediate statement of preferences in relation to a single event (e.g. choosing how to express or present oneself in a given instance, for example, whether to drink tea or coffee in the morning) and that an environment that supports continual episodic autonomy, for instance by encouraging someone to voice opinions, may lead to programmatic autonomy (i.e. making decisions about one's life direction, for example in terms of career direction or decisions about having children). ${ }^{21}$

Although expressions of episodic autonomy are contained to single situations, through these expressions, people come to better know their own desires and beliefs. ${ }^{22}$ Atkins speaks of the autonomy expression process articulated by Meyers as "socially-acquired competencies in critical skills of self-knowledge, communication and deliberation". ${ }^{23}$ Meyers asserted that socialization in the home is key to the development of the "environment" in which decisionmaking takes place and individuals who are not socialized to exercise episodic autonomy cannot develop the collection of skills needed for fuller, more programmatic autonomy competency. ${ }^{24}$ Development of competency hinges on the presence of a dialogical space, marked by opportunity to be answerable for choices and able to actively modify and control statements made about their lives and experiences. ${ }^{25}$ Suppressive social contexts can preclude the development of autonomy

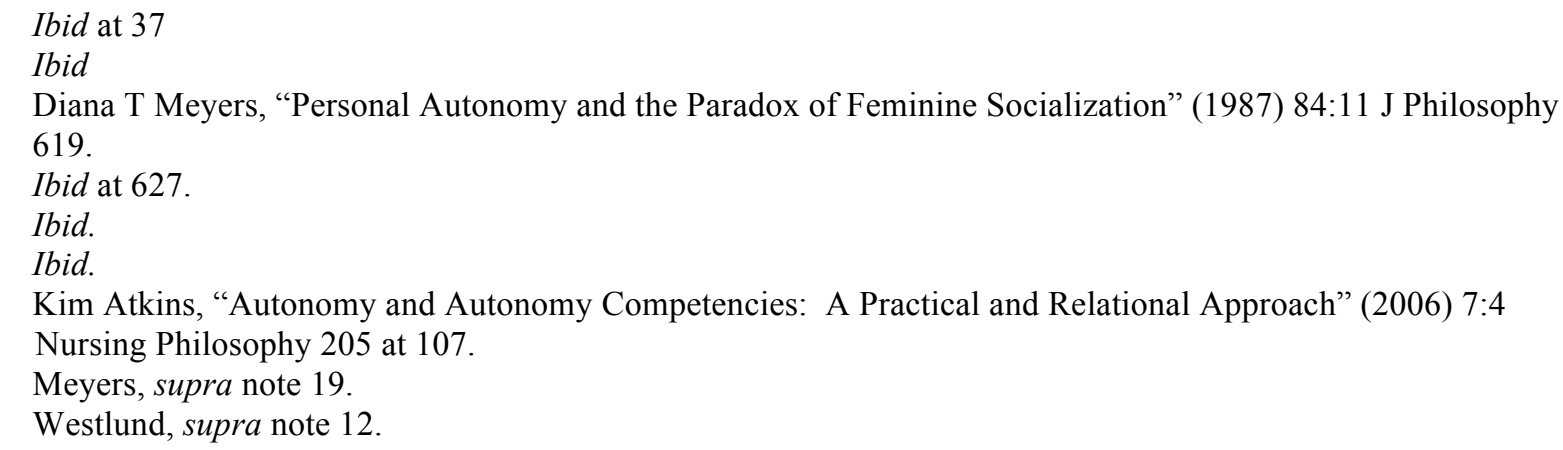


skills (self-reflection, clarification of preference) and prevent the exercise of autonomy. ${ }^{26}$ As such, social interactions may reinforce behaviours that are incommensurate with the development of competencies needed to define and assert one's wishes. ${ }^{27}$

\section{Relational Autonomy and Adults with Developmental Disabilities}

While concepts of relational autonomy, answerability and autonomy competency have been used extensively to understand experiences of women, these concepts are also vital to fuller understandings of adults with developmental disabilities whose experiences are often pervaded by social connections and interdependencies inherent to requiring day-to-day support.

\section{Adults with Developmental Disabilities and their Family Caregivers Defined.}

Developmental disability is a broad, categorical term that varies regionally and according to the health and social care providers, policy makers and researchers applying the term. We use the term developmental disability throughout our paper yet we acknowledge the limits of this term and the importance of scholarship that has advanced understandings of disability as "theoretically porous" 28 and we join with Garland-Thomson in viewing disability as a socially constructed experience that occurs in interaction with social and material contexts. ${ }^{29}$ For the purpose of this project, we use developmental disability to refer to conditions that are genetically based, lifelong, and entail some combination of intellectual impairment, communication deficit, and mobility limitation. Adults who have developmental disabilities require support and accommodation from multiple health and social systems. We define family caregivers as parents and siblings of adults with developmental disabilities who may be biological, step, foster or adopted, and who provide any combination of emotional support, companionship and instrumental assistance. ${ }^{30}$

Reliance on family caregivers complicates how society, including legal frameworks, judges the abilities of adults with developmental disabilities to be autonomous actors. ${ }^{31}$ Treating independence as essential to autonomy may include viewing the dependence of adults with developmental disabilities as an anti-requisite to autonomy. ${ }^{32}$ We counter views of dependence and autonomy as mutually exclusive and argue for a shift in emphasis onto the dynamic processes of relationships in support of viewing interdependencies of adults with developmental disabilities as components of their relational autonomy.

To our knowledge, disability researchers have yet to employ relational autonomy concepts to understanding adults with developmental disabilities and Westlund is distinct in having

26 Meyers, supra note 19.

27 Mackenzie \& Stoljar, supra note 3

28 Danielle Peers, Nancy Spencer-Cavaliere \& Lindsay Eales, "Say What You Mean: Rethinking Disability

Language in Adapted Physical Activity Quarterly" (2014) 31:3 Adapted Physical Activity 265.

29 Rosemarie Garland-Thomson, "Misfits: A Feminist Materialist Disability Concept" (2011) 26:3 Hypatia 591.

30 Karen Pyke "The Micropolitics of Care in Relationships between Aging Parents and their Adult Children: Individualism, Collectivism, and Power" (1999) 61:3 Journal of Marriage and the Family 661.

31 Carolyn Ells, (2001). "Lessons about Autonomy from the Experience of Disability" (2001) 27:4 Social Theory and Practice 599.

32 Ibid; Conway, supra note 1; Mackenzie \& Stoljar, supra note 3. 
illustrated answerability using the experience of an adult with a cognitive disability. Some disability researchers provide evidence of relational dimensions of decision-making by presenting findings of the ways in which family caregivers facilitate adults with developmental disabilities in feeling confident to share experiences and views with researchers ${ }^{33}$ as well as to make decisions about support needed from formal agencies. ${ }^{34}$ Alternatively, researchers present caregiving relationships in terms of potential to leave adults with developmental disabilities "compliant" and with restricted control over decisions in the presence of their more articulate family caregivers. ${ }^{35}$ Indeed, in making decisions, adults with developmental disabilities are likely to be supported as well as hindered by family caregivers.

In this paper, we interrogate interactions between adults with developmental disabilities and their family caregivers by using concepts of relational autonomy and autonomy competency. Specifically, we illuminate how family caregivers support, or hinder, the development of autonomy competency as we examine the ways in which adults with developmental disabilities express and enact episodic and/or programmatic autonomy in their family care contexts. We distinguish between "autonomy supporting" and "autonomy-hindering" and thus emphasize how family caregivers support or hinder the ability of individuals to be answerable, or to enter the dialogical decision-making processes, about their care and daily living and how this relates to their development of autonomy competency.

\section{METHODS}

\section{A. Data Collection}

We present a secondary analysis on a subset of data ( $\mathrm{N}=9$ participants from 2 families) collected for a larger study ( $\mathrm{N}=26$ participants from 7 families) that was aimed at understanding caregiving, care receiving and decision-making experiences of adults with developmental disabilities and/or mental health issues and their family caregivers as described by adults with developmental disabilities and/or mental health issues, their caregiving parents and siblings.

33 See e.g. Vicki Lloyd, Amanda Gatherer \& Sunny Kalsy (2006) “Conducting Qualitative Interview Research with People with Expressive Language Difficulties" 16:10 Qualitative Health Research 1386; Kath MacDonald \& Alison Greggans "Dealing with Chaos and Complexity: The Reality of Interviewing Children and their Families in their Own Homes" (2008) 17:23 Journal of Clinical Nursing 3123; Stacy L Nonnemacher \& Linda M Bambara, I am Supposed to be in Charge: Self-advocate's Perspectives on Supporting their Selfdetermination (2008) [unpublished, archived at Leheigh University, USA]; Michael Ruef \& Ann P Turnbull, "The Perspectives of Individuals with Cognitive Disabilities and/or Autism on their Lives and on Their Problem Behavior" (2002) 27:2 Research and Practice for Persons with Severe Disabilities 125.

34 Al Etmanski, Jack Collins, \& Vicki Cammack, Safe and Secure: Six Steps to Creating a Good Life for People with Disabilities, 1st ed (Burnaby, BC: Planned Lifetime Advocacy Network, 2003); Bonnie Lashewicz et al, "Understanding and Addressing Voices of Adults with Disabilities within their Family Caregiving Contexts: Implications for Capacity, Decision-making and Guardianship" (Toronto: Law Commission of Ontario, 2014).

35 Nonnemacher \& Bambara, supra note 31. Gillian Pascall \& Nicola Hendey "Disability and the Transition to Adulthood: The Politics of Parenting" (2004) 24:2 Critical Social Policy 165; Andrew Power, "Caring for Independent Lives: Geographies of Caring for Young Adults with Intellectual Disabilities" (2008) 67:5 Social Science \& Medicine 834 . 
Participants took part in in-depth interviews which were semi-structured to support rapport and allow flexibility of the interview structure around predetermined topics of living with and/or caring for someone living with developmental disability and/or mental health issues. As well as providing background information about family structure and support needs, participants responded to questions about their successes and struggles in giving and receiving support. Participants had a choice of three interview formats: 1) one-on-one interview with the researcher; 2) interview with the researcher together with one or more of their family caregivers; and/or 3) focus group interview - with or without one or more family caregivers - which included the researcher and participants from other families. This array of interview formats was used to obtain as many perspectives from within families as possible and in varying, interactive combinations. In designing our study to entail collecting data from people in interacting combinations, we were inspired by ethnographic approaches to immersing in the daily lives of participants

Data for the broader project were collected between 2010 and 2012 in two major urban centres and one smaller community in Alberta. Interviews were audio recorded and transcribed verbatim. Ethics approval for this study was provided by the Conjoint Health Research Ethics Board at the authors' University. Participants discussed and signed informed consent forms before each interview including the risk that given the small, in-depth nature of the study, even though participants are assigned pseudonyms in written reports, there is potential for participants to be identifiable by people reading the reports who know participants and/or their families. All participants signed "adult consent" forms while parents also signed "surrogate consent" forms on behalf of their family member with a developmental disability and/or mental health disorder.

Our subset of data from nine participants from two families was chosen for its potential to illuminate autonomy supporting and autonomy hindering family dynamics. Data from each of these two families included an interview from the adult with a developmental disability together with her parents in Family 1, and together with her parents and a sibling in Family 2. Through these group interviews, we were able to observe the dialogical processes through which adults with developmental disabilities expressed and enacted autonomy within their family care contexts. Data from the Family 1 also included one-on-one interviews with each of two siblings of the adult with a developmental disability regarding caregiving successes and struggles.

\section{B. Data Analysis}

Data analysis was conducted in two major phases: familiarization and conversation analysis. Familiarization entailed repeated listening and reading of interview audio and transcript files and broad organization, or chunking, of data according to particular topics such as "getting used to medication" or "managing unexpected travel". In our conversation analysis, we studied chunks of data with a focus on "turn taking" as articulated by Schegloff. ${ }^{36}$ Accordingly, we looked for evidence of rules and habits governing when people are empowered, required or allowed to talk

36 Emanuel A Schegloff, “Analyzing Single Episodes of Interaction: An Exercise in Conversation Analysis” (1987) 50:2 Social Psychology Quarterly 101. [“Single Episodes”]; Emanuel A Schegloff, Sequence Organization in Interaction: A Primer in Conversation Analysis (Cambridge: Cambridge University Press, 2007) [Primer]. 
next ${ }^{37}$ and, correspondingly, when people are expected to quietly agree with and submit to the communication of others. As we studied the flow of 'turns' (instances in which each participant spoke), we looked for evidence of episodic autonomy for the adults with developmental disabilities being supported or hindered. We examined language used by the adults with developmental disabilities and their family caregivers as they responded to questions and shared experiences, and we looked for how language - including non-verbal dimensions (such as stutters, hesitations and sighs) - was used. We present our findings from this analysis in the form of participants' patterns of "using each other's expectations about what comes after what". ${ }^{38}$

\section{Family Profiles}

\section{Family 1: Yvonne, Marcus, Amanda, Carrie and Andrew}

Yvonne and Marcus, who have been married for 35 years, head their family of five. Support for daughter Amanda, aged 33, diagnosed with a developmental disability, Obsessive Compulsive Disorder [OCD] and schizophrenia, defines much of family life for Yvonne and Marcus. Amanda has two siblings, Carrie, age 31 who lives with her husband, Matthew, and is expecting their first child, and Andrew, age 27, who lives on his own. Amanda lives with her parents, and Yvonne has been the full time caregiver for Amanda's entire life. Marcus recently retired from a 40-year career in financial services and is now more involved in Amanda's daily routines. Yvonne, Marcus and Amanda were interviewed together in the family home for two and one half hours. After the first hour, Amanda had her lunch then left with Marcus to be dropped at her day program. The interview continued one-on-one with Yvonne for 40 minutes until Marcus returned and rejoined the interview for the final 30 minutes. Carrie and Andrew were each interviewed one-on-one for 90 minutes, Carrie at a coffee shop and Andrew at the second author's office.

\section{Family 2: Daria, Michael, Sarah and Joni}

Daria and Michael lead their reconstituted and adoptive family in support for Sarah, age 20, who has a developmental disability. In addition, Sarah's sister Lisa, age 24, was labeled "gifted" when Lisa was in grade 7 and presented some distinct learning and social needs. Further, Lisa had sustained a brain injury four years prior to the interview but had since resumed much of her former education and work pursuits. Daria and Michael have been married 29 years and adopted both Sarah and Lisa as newborns. Three step-sisters to Sarah and Lisa, Joni, age 37, Rhonda age 38 and Jamie age 43, from Michael's first marriage, round out this family. Data from this family were collected in an interview in the family home lasting 2.5 hours that included Daria, Michael, Sarah, and Joni.

\section{Trustworthiness: Triangulation and Peer Debriefing}

Trustworthiness of data was enhanced by family triangulation; as such, having collected multiple perspectives from within each family, we were able to compare family member

Ibid.

38 Mark Rapley \& Charles Antaki, “A Conversation Analysis of the 'Acquiescence' of People with Learning Disabilities" (1996) 6:3 J Community Applied Social Psychology 207 at 211. 
perspectives of specific successes and struggles. Further, trustworthiness of analysis was supported through peer debriefing; analysis was led by the first author with regular collaboration with the second author who had collected the data. Debriefing discussions centred on comparing and converging our interpretations of participant meanings, particularly in instances when participant messages had been elaborated or modified by other participants. Analyses were further debriefed through presentations and discussions with our broader research team at monthly team meetings.

\section{FINDINGS}

\section{A. Preamble}

From our analysis we distinguish between "process" and "context" findings. In our process themes, we capture the dynamics of the dialogue between the adult with a developmental disability and her family caregivers and we delineate the ways in which the adult with a developmental disability exercised, or was unable to exercise, episodic autonomy. Consistent with conversation analysis, we concerned ourselves with features of the dialogue, such as who spoke first when an interviewer asked a question, who was interrupted, and who was corrected or spoken over.

In our context themes, we delineate features that 'surrounded' the dialogue, such as past histories of participants including previous life events and relationships between family caregivers and adults with developmental disabilities. Contextual data were coded through analysis of the content of participant stories of important events and ongoing trends in their relationships. Contextual themes are grouped into autonomy hindering (context features that contribute to denials of episodic autonomy) and autonomy supporting (context features conducive to the exercise of episodic autonomy).

\section{B. Dialogue Process}

1. Exercise of Episodic Autonomy by Making Corrections, Affirming/Disconfirming and Answering Directly

\section{(a) Making Corrections}

Adults with developmental disabilities demonstrated episodic autonomy by correcting statements made by their family caregivers pertaining to the preferences, life events, wishes and desires of the adults with developmental disabilities. This occurs frequently in the interview with Sarah and her parents and sister as Sarah interjects to correct points made by her family caregivers. For example, Sarah's father, Michael, describes having swiftly organized travel overseas in response to Lisa's having been badly injured in an accident:

Michael: Um, we booked Daria's flight immediately because I was, of course somebody was going to stay with Sarah, um, on the Saturday night and on the Sunday when I called my family back east, my sister immediately said she'd come out and get Sarah if we could get somebody to watch her for a couple of days so. 
Sarah: It was more like a month I think.

Michael adjusts: I'm sorry.

Sarah herself does not tell detailed stories but prefers to engage in sharing by "checking facts" embedded in stories told by her parents and sister. Indeed, Sarah makes corrections when family caregivers say things that Sarah does not consider reflective of her experience or preference and her style of narrative modification is aided by her family caregiver's openness to correction. This allows Sarah to exercise episodic autonomy by changing and directing the telling of her experiences, even if she is not the one telling the story from beginning to end.

Comparatively, in the interview with Amanda and her parents, we found no instances of Amanda either corroborating or modifying the narrative told by one, the other or both of her parents. In fact, Amanda has to work hard to have her voice heard amidst the conversation and most often, her views are heard only when the researcher directly asks her a question.

\section{(b) Affirming/Disaffirming Responses}

Sarah and Amanda assert their preferences and modify the responses of their family caregivers by using affirming or disaffirming non-verbal cues. The effectiveness of these cues depends on the extent of Sarah and Amanda's inclusion in the dialogue as well as the attentiveness of their family caregivers. In the interview with Sarah, her parents and sister, Sarah and her mother work together to describe Sarah's relationship with her sister Lisa:

Researcher asks Sarah: What about Lisa, like were you guys, um, Sarah did you sort of grow up like as partners with her or as best friends with her ever with your sister Lisa?

Sarah responds: We better, we bickered quite a bit.

Researcher: Is that, is that part of friendship or is that?

Sarah: Um.

Daria chips in: It is now.

Sarah affirms: Mm-hm.

In this instance, Sarah corroborates her mother's description with an affirmative utterance as a sign of her approval of the message delivered. Notable, although evident only on the audio file, is that Daria pauses at the end of her comment to await affirmation from Sarah.

In contrast, Amanda's affirming/disconfirming cues are not given the same level of credence as Sarah's. Often, Amanda's additions of "mhmm" and "ah" are ignored and not treated as reasonable attempts to shape the narrative being delivered by her parents. However, on occasion, Amanda uses affirming utterances to corroborate her parents' discussion points. In this instance, Amanda's father Marcus is describing a recent vacation including having been able to spend several days of the vacation alone with his wife while Amanda returned home with her siblings Carrie and Andrew:

Marcus: Yeah. 
Researcher: Okay. (to Amanda) You went (on the vacation) as well?

Amanda: Mm-hm.

Marcus expands: Well she, she came early with the kids.

Amanda: With Carrie and Andrew. Yeah.

Marcus adds: And we had four or five days on our own at the end of our stay.

Amanda: Mm-hm.

Here, Amanda, like Sarah, uses the utterance "Mm-hm" as a means of directing the flow of information. Yet, a key difference between Sarah and Amanda's use of such utterances is evident in the response of their families. Sarah's punctuation of the interview with "mm'hms" and "ums" resulted in pauses in the dialogue, allowing all participants to reflect on whether their explication of Sarah's experience rang true to Sarah. By comparison, Amanda's use of such utterances were attended to by the researcher, but not by her parents. Family caregiver pauses in dialogue for fact checking gives the affirming or disconfirming utterance its force; without a pause for acknowledgement, the affirmation has little modifying effect on the dialogue.

\section{(c) Direct Answers}

A third theme of adults with developmental disabilities exercising episodic autonomy is in the form of their having provided direct answers (or refusal of answers) to questions. This was evident when Sarah or Amanda responded directly to researcher questions without their family caregivers acting as intermediaries. Sarah's interview with her parents and sister reflects this theme, as Sarah often took charge in conversations that occurred in response to questions about her life, likes and dislikes. In this exchange that flows from Sarah having indicated that she enjoys creating artistic projects, the researcher asks to see a sample. Sarah without hesitation, refuses the reviewer request:

Researcher: Sarah, do you have any work samples of your Art?

Sarah responds: No.

Researcher appeal: Okay. Do you have any photographs of your work?

Sarah: No.

Researcher: Okay.

Sarah's direct and unapologetic response to this request is supported as her parents and sister did not interject to sway Sarah to comply with the researcher and, following the exchange between Sarah and the researcher, both Daria and Michael point out that Sarah has a longstanding practice of not sharing her art work.

\section{Denial of Episodic Autonomy by Speaking Over and Speaking For (a) "Speaking Over"}

Amanda is sometimes unable to exercise episodic autonomy as her voice is ignored during the interview dialogue. Amanda has difficulty making corrections or addressing questions directed at her as her parents tended to dominate the conversation without creating spaces for Amanda to 
contribute. Yvonne often ignores Amanda's contributions as reflected in an exchange where Marcus describes Amanda's typical morning routine:

Marcus: Huh and usually we'd be up and say come on Amanda time to get up, let's go, time to roll but now, you know now she's, ah.

Amanda: No, no, ah.

Yvonne: [But don't think everything's, um, a bed of roses. It certainly isn't. We have a lot of

Amanda: [No but.

In the quote above, Yvonne interjects and raises her voice over Amanda's, stating that the interviewer should not think "... everything's, um, a bed of roses..." before Amanda can even finish her corrective to her father's statement.

Amanda sometimes "outcompetes" her parents by being louder or faster in responding to the researcher. Such interjections by Amanda tend to be met with an awkward pause on the part of Yvonne such that Yvonne would wait expectantly for the first opportunity to continue with her own explication. In this way, Yvonne's silences while Amanda speaks mark instances where Yvonne is interrupted by Amanda rather than Yvonne having willingly allowed an opening for Amanda to speak.

\section{(b) "Speaking For"}

Episodic autonomy is sometimes hindered by family caregivers "speaking for" Amanda. Yvonne often denies Amanda the opportunity to share her own experiences by speaking on Amanda's behalf. When Amanda reflects on her adjustment to her anti-psychotic and anxiety medications, the following exchange occurs:

Amanda: I, it's, it's good. Um, I mean I have, I've been having breakdowns for a while with my voices and everything like that but I find that with my, um, new medicine I'm on, I'm on Anafranil and I've been on it for ages

Researcher affirms: Mm-hm.

Amanda: so I'm used to it but I'm on, um, oh I'm on, um, Abilify now so...

Researcher: Okay.

Amanda: and that kind of stuff, and Solexis so I'm still trying to get used to those two things but

Researcher: Mm-hm.

Amanda in response to Yvonne's sceptical look (documented in researcher field notes): what?

Yvonne: You're used to them.

Amanda: (Chuckle) Ah, not the Abilify and

Yvonne: Oh yeah you are.

Amanda: Oh yeah. Well anyways I, I'm on a newer medicine now and I find myself more aware. 
A further example occurs when Yvonne speaks at length about Amanda's experience with psychosis yet does not pause to allow Amanda to comment:

Researcher: ... and, and the well-meaning outsiders who say this, that and the other, they are even further removed from you know what that might be like.

Marcus: [Yes.

Amanda: [Yeah.

Yvonne: Well the one thing that was taught when, when you attend the support groups and, and trying to understand psychosis and that which I found was very interesting was pretend to be an interviewer and while you're interviewing, sit with headphones on and music playing constantly.

Researcher elaborates: Screeching, scream music in your.

Yvonne: Well just yeah music and still try to carry on a conversation and focus Researcher: Yeah.

Yvonne: and that is what the individual is going through while in a day to day routine.

Researcher: Yeah.

Yvonne: Granted, Amanda's voices aren't like that now and very,

Amanda: [Um.

Yvonne: you know breakdowns aren't that often. (to Amanda) Chew your food.

In both examples above, Yvonne's descriptions are not offered because Amanda is unable to describe her own experience; indeed, when given space, Amanda quite eloquently shares her thoughts and feelings, including about the string of anti-psychotic medications she has tried. Rather, Yvonne's interruptions serve as assertion of her opinion over her daughter's. Further, Yvonne's assertions tended to be followed by acquiescence on the part of Amanda who, after several unsuccessful attempts to interject her own views, ends up agreeing with Yvonne's version.

\section{Context}

1. Autonomy Hindered by Dominant Caregiving Identities, Caregiver Sense of Sacrifice, Disability Complexities and Family Expertise

\section{(a) Dominance of Caregiving Identities}

A key contextual factor in Amanda's difficulty asserting autonomy is the prominence of Yvonne in the dialogue and decision-making around Amanda's care. In the interview with Yvonne, Marcus and Amanda, as well as in the one-on-one interviews with Carrie and Andrew, it is clear that taking care of Amanda is the centre of Yvonne's life. Yvonne frequently refers to herself as "Amanda's caregiver" and emphasizes her dedication to her duties, and the fact that she was Amanda's main caregiver "from day one".

Yvonne not only takes responsibility for Amanda's care but also imparts a sense of ownership over it. Yvonne portrays other family and non-family caregivers as less capable, sometimes casting them as intruders or providers of unwanted help. She speaks of family dinners with 
Andrew, Carrie and Carrie's husband in terms of people coming over with unwelcome ideas of how to "fix" Amanda. Yvonne's wariness of caregivers other than herself even extends to her husband. During the portion of the interview when Yvonne is one-on-one with the researcher, she expresses surprise and dismay over how much Marcus spoke during the discussion about Amanda's care:

Yvonne: I am surprised that he talked so much and back, actually for him because he, he really is not involved. He was not involved in any meetings, any appointments, any nothing and now...

Researcher: Yeah.

Yvonne in a strained voice: ...it's frustrating when he gives all the talking and knows everything and yet

Researcher: Okay.

Yvonne: you know, yeah he,

Researcher: [Okay.

Yvonne: it's because of things that I have said that he's repeated

Researcher: Yes. Yeah.

Yvonne emphatically: but it certainly isn't him that has done,

Researcher: Okay.

Yvonne: you know he's been the breadwinner and that's the way it's

Researcher: Yeah.

Yvonne: been and I've looked after her and I still am and even now when he says about doing things, well let me see Yvonne, you can go back to work and I can drive Amanda and I go yeah but you're retired and you're telling me you're going to golf Monday, Wednesday, Friday and she's got to be somewhere at nine and you're going to go golfing at eight, how can I get a

Researcher: Okay.

Yvonne: job under those circumstances?

This exchange exemplifies Yvonne's feelings of singularity in understanding the nature and extensiveness of Amanda's care and the corresponding level of sacrifice needed to tend to Amanda's needs.

Amanda's brother Andrew characterizes the centrality of Yvonne's caregiving role as follows:

Andrew: My mom's a caregiver. That's her occupation. She's attached to that.

Researcher: Mm-hm.

Andrew: That's her definition as a person and you know specifically from what stuff I've read like men have jobs and their jobs are to earn income and take care of their family but

Researcher: Mm-hm.

Andrew: they're not defined by their job whereas women tend to attach themselves a lot more to their role right. 
The combination of Yvonne's self-definition as a caregiver and her scepticism about other potential sources of support create a family dynamic in which she is the chief authority on Amanda's care, and other family members in some ways compete with Yvonne for opportunities to participate in Amanda's care. For instance, Andrew comments that Amanda behaves differently while in his care. Contrary to his mother's opinion, Andrew believes Amanda could benefit from being pushed more. He illustrates through a description of his frustration with his parents' handling of Amanda's OCD symptoms surrounding food consumption:

Andrew: so her development I think which was, which has been stunted partly as a result of her condition for years, um, just ends up, ah, it just becomes really easy to stunt it because there's, there is no challenge. I was even, I was over at my parents' house the other night fixing my Mom's home or something and, ah, and it was Thursday and Amanda wanted a pop and this is and I can see how this would just tire my parents, having this conversation with her tired my parents. Like they didn't even have it, they were listening to me have it with her and I managed to only ask her questions and get her to rationalize that she had already had a pop that day, today was a Thursday, a weekday, Researcher: Mm-hm, mm-hm.

Andrew: how many pops should you have on a weekday? One, which is, that's a whole other fight but anyways, okay one.

Researcher: (Chuckle) Okay.

Andrew: Weekends two. Weekday one, great so how many did you have today? Well I had one so should you be able to have another one right now? No. Oh, okay, so you're not going to go get a Coke then right now right? Oh, well bro, you know it's like so I had to go through this three times and,

Researcher: Mm-hm.

Andrew: and walk her through it and eventually it was that, it was my parents that wanted me to stop because they you know frick, let her have a Diet Coke (chuckle) like is this the fight we really want to pick and that's, ah, that's I think part of the thing she gets at Carrie's [Amanda's sister] house and my house...

This is one of several examples where Amanda's siblings, father and mother declare expertise on aspects of Amanda's care. Yet amidst this expertise, Amanda's views on, or expressions of, her care needs are scarce.

\section{(b) Sacrifice and the "Life Un-Lived"}

In Amanda's family, Yvonne's sense of having made sacrifices in order to provide care hinders autonomy for Amanda. In describing her sacrifices, Yvonne justifies her position as central decision-maker in Amanda's life. In the following exchange, Yvonne speaks of having given up a professional life in order to care for her daughter: 
Researcher: Mm-hm. Okay. I'm just, overall I mean how has that felt for you in terms of identity? Um, you know as a woman

Yvonne: (Chuckle)

Researcher: as, ah, you know balancing?

Yvonne: This is where I'll probably cry. (Upset)

Researcher: Mhm. Sorry if, ah, you know I know that some of these reflections can get into some really emotional kind of sources.

Yvonne: Well as I basically have said you know my life was a caregiver. I never got to do what I wanted to do. What did I want to do now? Who knows. Even now trying to look for another job, Researcher: Mm-hm.

Yvonne: I don't know what I want to do....I, I think that's my biggest word over the whole is frustration as to what I would have, could have become.

In this way, Yvonne conveys having exchanged one life (the life of a working woman) for another (the life of a caregiver). Her feelings and actions of sacrifice form an important part of her identity and seem to contribute to her authoritative caregiving stance including in ways that hinder enactments of episodic autonomy for Amanda.

\section{(c) Complexity of Disability}

The complexity of an individual's diagnosed condition provides further justification for the caregiving dynamics in a family. Amanda's complex and "difficult" disability/mental health disorder is used to explain supplanting of Amanda's autonomy. Yvonne and Marcus frequently speak of Amanda, as "a lot of work", and describe Amanda's conditions as necessitating handson management and limiting future opportunities.

Marcus: We sometimes resign ourselves to the fact that this is as good as it's going to get so

Amanda interjects: I just need some learning and education

Marcus: Yeah.

Amanda holds her position: that's all.

Marcus counters: But you know that's where our frustration comes in sometimes Amanda because we try to point out things for you, um, like keeping your bathroom, um, the way you, you should eat, proper etiquette, this and that Amanda concedes: Mhm. Marcus: but our frustration is that we wind up telling you the same thing every day

Researcher attempts to support both views: Mm-hm, mm-hm.

Marcus: okay and because of your OCD I think sometimes and sometimes this stuff just doesn't register.

Amanda elaborates her position: I, I, sometimes I'm in a zone and I don't remember. I, I. 
There is a contrast between Marcus' view of Amanda's ability to develop and Amanda's view of her own potential.

The extensiveness of Amanda's needs necessitates that more decision-making power rest with family caregivers. Yet, Amanda holds out hope for her own progress, a hope that seems to collide with the resignation of her family caregivers. Thus the "difficulty" and "complexity" of a condition may provide more of a justification of the current caregiving dynamics, than a true reflection of what is possible for an adult with a developmental disability. Marcus illustrates this in his reflections on Amanda's future:

Marcus: Ah, I think going forwards what we'd like to do is see some focus on developing some independence for Amanda

Researcher: Okay.

Marcus: to the point of even maybe having her not be with us anymore but either in a shared environment or, ah, on her own with a, a, a roommate, ah, who would you know help look after her, things of that nature. Ah, beyond that, ah, every day of course we have to deal with the fact that Amanda does have issues ....and that she is on medicine and we have you know series of really, really good days and then we'll have days where Amanda will have a bit of a breakdown. Ah, we have, ah, sometimes issues with, ah, ah, behaviour.

While Marcus asserts his wish for Amanda to be more independent, he quickly undercuts that wish with an emphasis on Amanda's limitations.

\section{(d) "Family Knows Best" - Expertise of Family Caregivers}

Family suspicion and/or fear of non-family supports hinder opportunities for autonomy. While both families express reservations regarding Sarah and Amanda living independently, wariness of outside supports was pronounced in Amanda's family. Yvonne and Marcus worry over Amanda's difficulty with numbers and her overly trusting nature. Further, they express frustration that professional agencies devoted to supporting adults with developmental disabilities are not prepared to accommodate the volatility of Amanda's mental health condition and further, may even work in support roles for economic gain. Yvonne and Marcus discuss attempts to find supportive living arrangements for Amanda:

Yvonne describing the stance of professional agencies: Yeah, meaning "it's still your responsibility, we're not going to do anything for you, we can't do anything for you, there's no money to do anything for you" and so then Amanda took sick and then of course they're all saying to me and even Andrew and Carrie, like Mom and even her program is: "well I want to make sure she's stable before we start the procedure to find another place for her". Well is she ever going to be stable 
Researcher: Mm-hm.

Yvonne: so then you know then we go start a new drug last June. Well yeah she's stable now but that doesn't mean that two months from now she's not going to have a breakdown Researcher: Mm-hm. Yvonne:but in saying that trying to find, um, a, a supportive roommate, we saw the fellow next door go through the situation three times in one year.

Marcus, a bit later, adds: [Well the motiv-the motivation for some of these foster, Yvonne speaking over Marcus:[Supportive roommates.

Marcus: you know some of them were in it for the cash.

Worries about Amanda's cognitive and emotional difficulties along with misgivings about formal supports leave the great majority of Amanda's care in the hands of family. Amanda's exposure to outside caregivers, who may afford her more space to exercise episodic autonomy, is thus restricted.

\section{Autonomy Building}

\section{(a) Multiple Identities - A Life Outside of Caregiving}

A key difference between the two matriarchs in this data set (Yvonne and Daria) is the ways in which they define their identities as caregivers. Yvonne gave up paid employment and made caregiving her primary pursuit while Daria worked as a professional for many years before focusing her attention more extensively on Sarah. More recently, Daria provides consultation to families of children with developmental disabilities pertaining to protocols for financial management and applications for formal supports. As such, notions of sacrifice and family caregiving intensity are more pronounced for Yvonne.

Further, Daria's professional pursuits required her to spend time collaborating with her older stepdaughters in providing care to Sarah as well as Lisa. Daria frequently refers to how "wonderful" it was for her daughters to "come and look after [Sarah and Lisa]", and portrays a positive experience with handing off caregiving duties. This history of teamwork, established in part by the necessities of being a working mother, extend to all members of Sarah's family. As such, there was no dominant caregiving voice, but rather everyone was involved in, and respected for their contribution to, Sarah's care.

\section{(b) Facilitation by Caregivers}

Autonomy building occurred as family caregivers supported the adult with a developmental disability to speak by using verbal encouragers or pauses which allow the adult with a developmental disability to enter the dialogue. In Sarah's family interview, Daria and Joni encourage Sarah to discuss to whom Sarah feels closest:

Researcher: [Sarah, can I just ask to you, um, about your sisters. Um, you know do you confide in your sisters or do they help you or do you help them, like does, 
what stands out

Sarah: [Mhm.

Researcher: for you in that way?

Sarah: Mhm.

Researcher: Do you phone your sisters?

Sarah: Um, no.

Researcher: Do you look forward when they come to visit?

Sarah: Yes.

Researcher: Okay. Um, does any one name kind of stand out that you know you really are excited if?

Sarah: Um, no it's, not really.

Researcher: Okay.

Joni: You won't hurt my feelings. You can say it.

Daria: You can say it.

Sarah: There is no name that stands out.

Joni: You don't look forward to Lisa coming more?

Sarah: I do but I just...

Joni: Yeah.

Sarah: there's too many people in my family.

Sarah's family creates a supportive space for her to exercise episodic autonomy by sharing her opinions. Reassurances of "you won't hurt my feelings" and encouragement of "you can say it" open the dialogue on this sensitive subject such that Sarah can offer her opinion. Sarah's family respect Sarah's reluctance to speak, signified by Joni's reassuring "yeah" when Sarah answers after some hesitation. As such, family encouragement is tempered by respect for Sarah's boundaries. Caregiver facilitation then, goes beyond helping an adult with developmental disabilities find the correct words or aiding in communication with the researcher and extends to creating the type of conversation in which that adult feels comfortable.

\section{DISCUSSION}

The two caregiving families comprising our sample have much in common as middle class, intact families who have provided lifelong care to a daughter/sister with a developmental disability. Yet, by having delved into obvious and subtle dynamics of each family's communication, we are able to present a dichotomous model where we distinguish process and context themes as reflective of "competitive" versus "cooperative" dialogue (see Table 1). Competitive dialogue is evidenced by a division of roles, where one or two individuals are the clear leaders of the conversation and others struggle or compete for the opportunity to steer the dialogue. Correspondingly, leaders resist relinquishing "the floor" and having their ideas modified. In contrast, cooperative dialogue is marked by facilitation of multiple points of view, an absence of a dominant voice, and an openness to modification and redirection. 
Contrasting dynamics in our two families represent positions on a continuum between our model types with Amanda's family approximating a competitive dialogue and Sarah's illustrating a version of cooperative dialogue. Amanda and Sarah have markedly different experiences with being included in conversations about their care and ultimately, in controlling their personal stories. Sarah displays assertive behaviour as she directs descriptions of her life and characteristics, enacts her desire to speak (or to remain silent) and enforces boundaries. Sarah's behaviour occurs within the context of a family that creates a space for her to exercise autonomy and in which contributions of each member are met with comparable regard and attention. By contrast, Amanda struggles to assert herself, frequently competing with, or working against, her parents in an attempt to speak her mind. Specifically, Amanda's efforts to be heard occur in a context where one caregiver voice - Yvonne's - dominates the conversation around Amanda's care, making Amanda's attempts to exercise episodic autonomy difficult.

Table 1: Key Features of Cooperative and Competitive Dialogue

\begin{tabular}{|l|l|}
\hline Cooperative & Competitive \\
\hline $\begin{array}{l}\text { Family caregiver facilitation of voice and } \\
\text { the creation of a "safe space" for open } \\
\text { dialogue }\end{array}$ & $\begin{array}{l}\text { Lack of facilitation of speech and no active } \\
\text { attempt to encourage the assertion of } \\
\text { opinions and personal stories }\end{array}$ \\
$\begin{array}{l}\text { Collaborative or team environment where } \\
\text { all voices are heard and appreciated }\end{array}$ & $\begin{array}{l}\text { A leader-based approach where all } \\
\text { participants refer to, or compete with, a } \\
\text { dominant voice/voices }\end{array}$ \\
\hline $\begin{array}{l}\text { Openness and receptiveness to correction } \\
\text { and modification by the adults with a } \\
\text { developmental disability }\end{array}$ & $\begin{array}{l}\text { Corrections and modifications from the } \\
\text { adult with developmental disability } \\
\text { ignored or responded to defensively }\end{array}$ \\
$\begin{array}{l}\text { Active attempt to make the adult with a } \\
\text { developmental disability the centre of } \\
\text { dialogue surrounding their care }\end{array}$ & $\begin{array}{l}\text { Little attempt to make the adult with a } \\
\text { developmental disability central to } \\
\text { dialogue surrounding their care }\end{array}$ \\
\hline
\end{tabular}

While our sample is small, our data is richly detailed and illuminates contrasts between families that allow us to conclude that cooperative dialogue promotes expressions of episodic autonomy and development of autonomy competency by adults with developmental disabilities. Cooperative dialogue as a model for supporting the exercise of autonomy reflects Westlund's concept of answerability as well as Meyer's concept of autonomy competency. ${ }^{39}$ Cooperative dialogue creates a context where adults with developmental disabilities are supported to exercise their episodic autonomy by stating preferences, making choices and, in essence, owning personal narratives.

39 Westlund, supra note 12; Meyers, supra note 19. 


\section{IMPLICATIONS FOR LEGAL FRAMEWORKS AND ONGOING RESEARCH}

Canada's 2010 ratification of the United Nations' Convention of Rights for Persons with Disabilities [UNCRPD] catalyzed a renewal of legal consciousness about protecting and building inclusive societies. As Bach and Kerzner note, the supported decision-making component of the UNCRPD compels a shift from the determination of incapacity, to the provision of supports and reflects a philosophical appreciation for the relational nature of decision-making. ${ }^{40}$ The uptake of supported decision-making varies by region of Canada ${ }^{41}$ and we take the opportunity of this formative "moment" to recommend an additional layer of attention be given to the dynamics of support relationships. Bach and Kerzner point to the facilitative potential of close relationships, noting that someone "in an individual's support network is likely much more effective at communicating with the person than anyone else". "We agree, yet caution that drawing on close relationships raises potential for pre-existing relationship patterns to be enacted in ways that may support or hinder adults with developmental disabilities in expressing and enacting autonomy. Indeed, it is not only adults with severe communication impairments, and adults living in abusive and neglectful environments, who need an attentive legal response towards helping them have their choices honoured. As we assess the extent and effectiveness of "supportive" decisionmaking, we would be wise to attend carefully to adults with developmental disabilities whose support relationships are characterized by competitive dialogue.

Understandings of the workings of relational autonomy for adults with developmental disabilities are in early development and we recommend not only continued study of adults with developmental disabilities in their relational contexts but also greater attention to the complexity of relational processes, and we believe conversation analysis approaches may be fruitfully applied to this endeavour. Conversation analysis is anchored in the principle of people achieving meaning by "actively using each other's expectations about what comes after what". 43 Because this approach compels detailed study of lengthy exchanges of communication, including verbal and non-verbal dimensions, we believe findings from such analysis can continue to inform legal frameworks and elaborate on our dichotomous model for thinking about distinctions between cooperative and competitive dialogues.

\section{CONCLUSION}

In examining dynamics and implications of relational autonomy in decision-making by adults with developmental disabilities in interaction with their caregiving family members, we underline the importance of caregiving contexts in fostering relational autonomy in adults with developmental disabilities. In our specific cases, caregiving relationships defined by cooperative dialogue facilitated greater exercise of episodic autonomy and therefore more opportunities to

$40 \quad$ Bach \& Kerzner, supra note 9 at 56.

41 Ibid; Shirli Werner, "Individuals with Intellectual Disabilities: A Review of the Literature on Decision-Making Since the Convention of Rights of People with Disabilities (CRPD)" (2012) 34:2 Public Health Reviews 1.

42 Bach \& Kerzner, supra note 9 at 49.

43 Rapley \& Antaki, supra note 38 at 211. 
develop autonomy competency over time. Contrastingly, caregiving contexts in which the dominance of caregivers' identities led them to direct and control the flow of dialogue created barriers to the exercise of episodic autonomy. As such, we posit that cooperative dialogues can foster the exercise of autonomy in adults with developmental disabilities and add that the potential for cooperative dialogues to foster the exercise of autonomy extends to populations with a host of "disability" diagnoses including dementia, brain injury and - as we illustrated in light of Amanda's multiple diagnoses - mental health disorders. Given the relevance of our analysis for laws pertaining to guardianship and shared decision-making, continued study of relational autonomy in the context of caregiving relationships with larger, more diverse samples is needed. Such research will further illuminate relational autonomy "capabilities" and contribute policy relevant understandings of adults with developmental (and other) "disabilities" as capable people. 